\title{
Rethinking 3.11's Mediascape through Japan Sinks 2020
}

\section{Yaochong Yang}

Volume 2, Pages 92-120

\begin{abstract}
This paper examines Science SARU's Netflix show, Japan Sinks 2020, notably its departure from the general apocalyptic ideology of previous primary Japan Sinks texts. By reframing it through the disaster lens of 3.11, Japan Sinks 2020 sheds light on significant inequalities between global and regional images. As the first internationally aired Japan Sinks media, Japan Sinks 2020 leverages contemporary streaming practices to propose ongoing counter-narratives of the Japanese state, its actors, and the urbanrural divides which have preceded - and continue - in the face of 3.11. Drawing upon Komatsu's last words on the international status of the 3.11 disaster, Japan Sinks 2020 is a post-3.11 text addressing aspects of Japanese disaster fiction mainly ignored by previous Japan Sinks texts and simultaneously reignites less-discussed challenges associated with the 3.11 mediascape.
\end{abstract}

Keywords: 3.11, Japan Sinks, Disaster fiction

\section{Author Bio:}

Yaochong Yang is a PhD Candidate at Trent University.

This work is licensed under a Creative Commons Attribution-NonCommercial 2.0

\section{Generic License}




\section{Intro}

Science SARU's 2020 Netflix series Japan Sinks 2020 ends with the Japanese returning to a re-emerging Japan. The soundtrack is uplifting. Ayumu, one of the survivors, narrates the hopefulness of her country. This narration is juxtaposed with images of submerged buildings - a stadium, Tokyo tower, the Tokyo Skytree - and then it pans up above the waves to reveal a clean, modern Japan, floating on rafts. At the center is a new Tokyo tower, indistinguishable from the old. In this very brief sequence, Japan Sinks 2020 not only reminds its viewers of the life, land, and relics lost, but also the paradoxical position of Japanese disasters: the consistency in which they occur, but also the readiness in which they are seemingly forgotten.

An interpretation of disaster recovery after 3.11, Japan Sinks 2020, recalling Sakyo Komatsu's final words on country's international image during the disaster, problematises ongoing narratives in the 3.11 mediascape. In a dramatic departure from previous Japan Sinks texts, the show's depiction of rural decay, as well as its emphasis on violence and long-term disaster care, suggests that there are still lessons from Tohoku remaining to be learned. The lessons, given the show's broadcasting during the postponed Tokyo Olympics, suggest a rethinking of the narratives around 3.11, particularly in the face of waning national and international interest as well as a spotlight on unseen instances of violence after the disaster.

In this sense, Japan Sinks 2020 serves as a reminder of the plight of 3.11. However, as a Netflix special, broadcast internationally for the world to see, who is it reminding? It is Japan - and Japan only - that sinks and re-emerges. Why is it, therefore, broadcast on a global platform? What is it broadcasting? As a Netflix Original, shows developed and broadcasted specifically for Netflix's catalogue, Japan Sinks 2020's initial release was not 
limited to a specifically Japanese audience, but a global audience. At the same time, the show carries political antecedents specific to 3.11 Japan. In other words, Japan Sinks $202 O$ acts as both a snapshot to the Japanese response to 3.11. Yet by focusing on lesserdiscussed aspects of 3.11, it also emphasizes the recovery logic of the disaster. It accomplishes this through an interlocked focus between body and nation, generating a form of counternarrative to the Tokyo-based, conservative, gambare messages that emerged in Japanese media.

\section{Context}

Originally published as a novel in 1973 by highly influential science fiction writer Sakyo Komatsu, the original Japan Sinks on a pair of scientists who must develop a solution to save the islands. Like Japan Sinks 2020, the islands sink. A film by director Shiro Moritani was released the same year with a similar plot. Both Komatsu (and subsequently Moritani) were grappling with a post-war Japanese identity, specifically in the wake of the 1964 Tokyo Olympics ${ }^{1}$ and the 1973 Oil Crisis. ${ }^{2}$ Both the novels and films would stress a concurrent fixation with a national and international Japanese identity, a concern which Japan Sinks 2020 takes advantage thanks to its unique characteristic as an internationally broadcasted Japan Sinks property.

The role of Japan Sinks 2020 as a form of broadcast becomes even more relevant considering that, shortly before he passed away, Komatsu Sakyo's last written work directly discussed the very broadcasting of 3.11. On March 11, 2011, an earthquake measuring 9.0 on the Richter scale struck off Sendai's coast. It sent tsunamis up to $120 \mathrm{ft} 3$ high deep into the Tohoku (northeast) area of Japan. Due to the disaster and a series of safety management failures, three out of the four reactors at the Fukushima Daiichi plant 
underwent a meltdown, spilling radiation into the surrounding countryside. The Tohoku Triple Disaster, more generally known as 3.11, resulted in 18,500 casualties, half a million displaced peoples, and $\$ 210$ billion in damages. ${ }^{4} 3.11$ remains the costliest natural disaster in human history, and the subsequent radiation spillage and cleanup is an ongoing expenditure for the Japanese government. 5 In an anthology titled 3.11 no Mirai ("The Future of 3.11"), Komatsu notes that while previous significant disasters in Japan were publicly and internationally known, the Tohoku triple disaster dwarfed everything preceding it. The international and incessant broadcasting of 3.11 caused lasting consequences on Japanese national identity to a degree never seen before - what is the world seeing? ${ }^{6}$ How is it responding to this disaster? Most importantly, what kind of Japan is being shown?

After 3.11, a particular set of Tokyo-based, ethnonationalist narratives emerged, partly out of a need to press a unified national identity as part of the country's reconstruction. Tamaki Mihic notes that a nationalist rhetoric emerged out of the Tohoku triple disaster, leading to a resurgent sentimentality of Japaneseness through an aggressive use of the word kizuna.7 However, what amplified the sense of a unified Japanese response was an international perception of Japan as a calm, collected, and united people. ${ }^{8}$ The nationalist image, in effect, folded in on itself; not only was there a massive internal push by the Japanese government to come together, but there was also an international image which pushed the Japanese to conform to a particular disaster nationalist identity. Yuko Nishimura, a Tohokuite who worked with local recovery efforts around Rikuzentakata, mentioned a similar embarrassment. She notes that the international sympathy was a point of self-consciousness to many Japanese, 9 especially considering that the hardest hit area was Tohoku, which was historically a peripheral 
zone. ${ }^{10}$ Both Mihic and Nishimura are tackling similar problematics in much of the mainstream post-3.11 rhetoric: there was a need by certain political actors for a resurgent, homogenous Japan in the face of both widespread devastation as well as mounting international expectations on the Japanese struggle. However, such desires and expectations effectively hide regional dynamics as well as marginalize critical actors in the wake of 3.11's reconstruction.

Japan Sinks 2020 effectively broadcasts an alternative narrative against the reconstructive logic of 3.11. It accomplishes this through a depiction of alternative subjects. In doing so, Science SARU is pushing back against the image of a holistic Japanese identity. More specifically, the show accomplishes this not only through a direct foregrounding of Japanese racial relations, but also stresses existing tensions between core-periphery imaginations, especially urban-rural divisions.

\section{Rejecting Visible Collapses}

Much of this foregrounding occurs thanks tothe show's position as a text within a global technocultural flow, what Arjun Appadurai calls a mediascape. ${ }^{11}$ Japan Sinks: 2020 heavily fixates on narratives mediated by screens - screens of smartphones, tablets, and game consoles dominate the show, reaffirming the highly technological relationship between 3.11 and its international audience. For instance, one of the survivors shows footage, by a Youtuber named Kite, of Okinawa's sinking. The Japanese are getting video footage of Okinawa sinking, not from the government or a Japanese outlet, but Kite, an Estonian YouTuber. They are already linked into a global mediascape, though because the footage is too harrowing to grapple with, they reject it as an attack on their own national identity. And yet, at the same time, they cannot disconnect themselves from that feed. 
Characters are watching the footage, not negotiated through the lens of a Japanese content creator, but from a foreign content creator, and nevertheless craft their own narratives. In this scene, the assumed viewer is not just people watching the show, but also, more generally, any audience member who witnessed the disaster of 3.11, both directly or allegorically (through Japan Sinks 2020). In other words, survivors watching the sinking of Okinawa are not that distant from both the Japanese and international audiences watching the floods on any video and broadcasting platform (including Youtube), and even more closely, drawing their own conclusions on the disaster.

In this sense, the show's subject - and the subject of these screens - are not just conventional disaster narratives that generally populated previous Japan Sinks. These seemingly perennial subjects of Japan Sinks - urban imaginations, technocratic responses, and disaster macropolitics - play much more limited roles in Japan Sinks 2020. Part of the move away from urban imaginations of 3.11 may stem from creative decisions. Director Masaaki Yuasa has mentioned that he largely remembers 3.11 from Tokyo, outside of the disaster zone.12 Since Tohoku is one of the least populated areas with some of the lowest average incomes in Japan, ${ }^{13}$ a depiction of 3.11 through disaster means focusing much less on urban regions and shedding more light on rural areas, specifically rural disasters.

The move away from urban imaginations towards rural ones is recollective of what both urban planner Aoi Akihito and disaster journalist Watanabe Minoru refer to as visible and invisible collapses. The former refers to visible destruction - images of rubble, bodies, and destruction. Japan Sinks 2020's opening episodes grapple with bombastic, visible destruction. At the end of episode 2, people are seen falling from the streets from some unknown force, which is revealed to be a rampant fire whirl. The crashing 
helicopter, downed plane, and collapsing stadium during the initial quake are reminiscent of the previous Japan Sinks films, of which both the 1973 and 2006 versions bear prolonged scenes of buildings collapsing, people stuck in rubble, and long lines of scattered civilians. The depiction of invisible collapses is particularly salient since previous Japan Sinks visual media have largely opted to tackle visible collapses; both Moritani and Higuchi's 1973 and 2006 films (respectively) opt for showing widespread destruction and chaos. Fire and rubble are ongoing visual cues of visible collapses in previous films, since audience members can directly and easily associate disasters with these signs. However, given the peripheral location of Tohoku (relative to Tokyo) and the ongoing problems with radioactivity, the visual imagery of Japan Sinks 2020 is much more subdued. Given that the initial episodes begin with a strong visual emphasis on fire and rubble, recollective of Higuchi's 2006 opening, the Mutous' trek into the countryside suggests a stark visual rejection of what can be considered an urban imagination of disaster. The show takes advantage of what Lamarre refers to as animetic movement the sliding of cell layers as a form of technical motion ${ }^{14}$ - landslides and water dominate the show's disaster imagery, and the destruction of the massive kintsugi Jomon statue splits along layers as it slides into the fissures of the ground. In this sense, Science SARU adopts a decidedly rural visual turn; the rejection of the urban imagination is interimplicated with a rejection of the cinematic imagination which has dominated previous Japan Sinks films.

As the Mutous move into the countryside, the show's adoption of increasingly invisible collapses become clearer, beginning the counter-narrative broadcast of 3.11's recovery logic. For instance, though the disaster begins in urban environments, the effects and consequences of that destruction are shown in rural areas. A later scene suggests 
that such rural decay was an ignored problem , an issue which preceded the sinking of Japan. When the old proprietor of the department store takes him to a cemetery, the graves are depicted as worn out. The suggestion is that there were very few people left to maintain it. The old man presents a different response vector: instead of the Mutous, who have evacuated in the face of disaster, he refused to leave his home and the remnants of his family. His life was upturned by the sinking of Japan, but the sinking merely served as the final nail in the coffin of a long string of problems. A victim of a disaster long before the actual events (whether it is the declining rural countryside or another, separate earthquake), his presence in the show presents the disasters in Japan Sinks: 2020 not as a series of discrete scenarios puncturing a moment's peace, but instead as a seamless fabric of inter-implicated problems. Compared to previous Japan Sinks films, Science SARU's Japan is one whose pristine condition never existed. Though the first episode's events revolve around the Mutous getting out of the city, their exodus is not presented as a pilgrimage towards safety, but a de-privileging of an urban imagination as it faces an ongoing rural one. In this sense, the show adopts a somewhat surreal, atemporal depiction of disaster; by offloading the consequences of disaster to rural areas, the show makes it exceedingly difficult to know what is and is not caused by the literal sinking of Japan. Much of the countryside is presented as post-disaster, empty and languishing, with few survivors.

A similar post-disaster imagery was mentioned by Yuko Nishimura as she recounted her relief efforts in Tohoku. By emphasizing the rural disaster, Japan Sinks $202 O$ strives to more accurately depict new and ongoing problems that arose out of 3.11 and sheds light on regional inequalities within the country itself. In a retrospective on reconstruction efforts in the Tohoku area, Nishimura notes that while many Japanese 
welcomed the initial outpouring of sympathy, it also inadvertently effaced real regional identities. She states that, "many Japanese may have felt self-conscious, embarrassed or even ashamed by the international outpouring of sympathy since it was mostly the Tohokuites of three prefectures in the north who were the victims, and not the Japanese as a whole." 15 In fact, despite being a native of Tohoku herself, Nishimura was unable to hide her surprise upon arrival at Rikuzentakata, noting that she "felt [she] was in a nightmare, a surreal story in which the entire planet had been destroyed by the atom bomb."16 To Nishimura, such images were mediated through an urbanized lens, that the situation is less one of ongoing regional exploitation and subservience towards a Tokyobased core and instead an immediate, singular disaster that must be rectified immediately. Japan Sinks: 2020 problematizes the spectacle of catastrophe - rural Japan, it suggests, was not dying because of the disaster; it was already dying.

\section{Invisible Collapses and Unseen Victims}

The move towards rurality in Japan Sinks: 2020 shifts away from discourses around large, macro destruction towards more micro and long-lasting destruction. It operates as a counter-narrative through a depiction of subjects and spaces often ignored in previous Japan Sinks texts, primarily issues of rural disasters, sexual violence, and radiation.

For instance, in one episode, the Mutous catch a wild boar. The scene is played in a heartwarming fashion with an uplifting beat by Kensuke Ushio. It depicts city folks who ultimately triumph in the face of adversity. However, while the boar scene is relatively lighthearted, it signifies Japan's ongoing rural plight. The emigration from certain parts of Tohoku (due to the radiation) has resulted in an explosion of the wild boar population. ${ }^{17}$ 
Yet more distressingly, the wild boars were not caused by the events of 3.11 - they were already endemic to rural Japan. As Japan's youth move towards the cities, the average age of Japan's towns skews much older, and as a consequence, such towns are becoming overrun by wild boars. ${ }^{18}$ Here, the boar scene behaves similarly to the initial urban destruction of Tokyo, though it presents an admittedly different side of the surrealist imagination. As the song swells, the scene takes on an adventurous, light-hearted tone. As the father, Koichiro, hangs on to the boar, the family tries to help him. The scene then cuts to the boar cooking on a grill, with few additional details. The sequence, in effect, takes on a dreamlike quality, distilling any distinct sense of time and space into a sequence without a clear beginning and end. What led the boar there? Was it the sinking of Japan? Or was it always there? The show makes no effort to clarify it, though it draws upon this real issue to address some of its concerns.

While the boar scene serves as a short signifier for Japan's rural decay and the urban imagination's inability to grapple with it, Japan Sinks 2020 tackles with subjects of sexual assault and radioactivity as central components of invisible collapses. Journalist Watanabe Minoru, who has spent much of his time on invisible collapses in the context of the 1995 Awaji-Hanshin quake, describes it as a situation where the rules of society begin to crumble ${ }^{19}$ and where self-justification of criminal actions emerges. ${ }^{20}$ Since many invisible collapses are long-lasting and unseen, they are much more difficult to depict in media. Furthermore, because invisible collapses are ongoing problems, providing solutions to them is incredibly difficult and costly. The Tohoku triple disaster magnifies the long-lasting issues associated with invisible collapses for three general reasons. One, because the event was, as Komatsu notes, broadcast internationally, there is a real political incentive for Japanese media to depict the survivors as calm and collected. 
Second, because the disasters struck some of Japan's most impoverished areas, these media are dealing with a departure from the disaster imaginations gestated in the urban cores. Third, due to the radioactivity resulting from the Fukushima-Daiichi meltdown, the scope of the disaster's damage is not just massive and immediate; there is a long-term socioeconomic discombobulation and displacement that occurs. Japan Sinks 2020, in a departure from the Moritani and Higuchi offerings, devotes significantly more time to the latter.

The invisible collapse does not mean that the images of calm and collected Japanese are necessarily false. As Nishimura points out, the Japanese's international image during the 3.11 disaster was, truthfully, one of a calm, collected, coordinated effort by everyone involved. ${ }^{21}$ Tamaki Mihic makes a similar observation, noting a dramatic selfperception emerged as "images of the cool, calm and collected response of the Japanese to the 3.11 disaster impressed the world." 22

However, just as how the rural imagination can be seen as a counter-narrative against the prevailing urban imagination, the depiction of the Japanese as neither calm, cool, nor collected positions Japan Sinks: 2020 as an important broadcast of another counter-narrative. In fact, the show rejects the notion that disasters have an ontological limit, that they can be 'over'. The show accomplishes this rejection through two notable examples of invisible collapses: sexual assault in the midst of a disaster and radiation.

In Japan Sinks: 2020, there are two instances of attempted sexual assault, though the first instance is particularly relevant because it also outlines the ideological context in which perpetrators commit these acts. In episode three, the Mutous (along with a few friends) hitch a ride from a trucker, who is drinking. One of the friends chastises the trucker for drinking while driving, after which he argues: 
There are no cops anymore...because of you guys, I'm a little over carrying capacity, so who cares about those silly little laws? Let's do all the things we couldn't do before. You're losing out if you're not having fun!23

The show employs a conventional approach to signal the driver's ill-intent; it adopts the driver's first-person perspective and tilts the camera bottom to top, fixated on the body of Nanami, family friend of the Mutous. Viewers cannot stop him nor get involved, even as they are aware of his intentions. In the next scene, they park at an abandoned gas station, at which point he forces himself upon her. Mari and Ayumu stop him, take his truck, and leave him stranded. If we consider sexual violence during (and after) disasters as fomented sites of invisible collapses, the witnessing of Nanami's attempted sexual assault becomes not only a grave reminder that victims do face considerable unreported and undocumented violence in the wake of these disaster, but also that it was thanks to the concerted effort by Ayumu and Mari - other survivors and potential victims - that she was able to avoid this fate.

In that sense, the sexual assault sequence reflects the sentiment of scholar Meiko Yoshihama, who notes that one of the major problems that arise out of disaster is "a wide range of abuse and exploitation, including quid pro quo sexual assault, where threats were used to force compliance in exchange for shelter, food, and other life-sustaining resources,"24 which is particularly important considering that this transactional exploitation happens outside of the view of mainstream media and governmental response. Reporter Rob Gilhooly similarly notes that after the initial disasters of 3.11, Japanese women become victims of an ongoing slew of sexual abuse, harassment, and rape. 25 Both Gilhooly and Yoshihama's accounts are in stark contrast to the narratives 
mentioned by Yasuda et al, who note that the National Police Agency concluded that while such incidents did occur, most of them were deemed groundless. ${ }^{26}$ The problem, the NPA reasoned, is that such claims could exacerbate problems and cause panic. Yoshihama notes that such insistences may be an attempt to control the disaster narrative. ${ }^{27}$

Between these two competing claims about the prevalence of sexual violence after disasters (especially 3.11), Japan Sinks 2020's decision to show attempted sexual violence twice reaffirms its status as a counter-narrative. The first scene not only suggests that it is primarily survivors who must undergo the role of physical and emotional support, but it also acts as a move away from the technocratic imaginations of the Japanese government. The existence of a second scene, where Ayumu is the victim, delegitimizes any claims that such cases are anomalous. Both sexual violence cases in Japan Sinks 2020 are not resolved by the government, but other victims of the disaster. The show's depiction of sexual violence acts as a direct counterpoint to some of the ongoing narratives after 3.11, particularly some of the political interests in focusing less on sexual violence and instead depicting the Japanese as calm and collected.

\section{Recovery Logic}

In addition to sexual violence, Japan Sinks 2020 also briefly touches upon another aspect of invisible collapses: radiation. Compared to previous post-war disasters, 3.11 is unique to Japan precisely because of the Fukushima-Daiichi meltdown. The effect of the radioactive spill is that many victims may be unable to return to their former lives. As a result, an identity of displacement emerges from many of 3.11's disaster victims, who must seriously consider whether they can "move on" and settle somewhere else or whether they must come to a plan as to how to return. Akihito describes this mentality as hinan shakai, 
or evacuation society, where people are stuck in stages of temporary housing, forced anonymity, and long-term precarity. ${ }^{28}$ To some, losing everything and living out the rest of your life in a hostile environment can prove too much: Hamako Watanabe, who committed self-immolation after the loss of her home, is one such consequence. ${ }^{29}$ What underlies all of this is a concern with recovery - where to recover, recovering with whom, and what one considers recovery. Anne Allison has touched upon similar concerns in Precarious Japan, noting that the precariousness facing all Japanese were not just in the immediate dangers, but persisting dangers which can extend even to those outside of the immediate disaster zone. $3^{\circ}$ In this sense, the concept of evacuation and recovery is not just simply a sense of recuperation, but also to adorn a new identity of susceptibility: susceptibility to harm, disease, and death. ${ }^{31}$

This adoption of harm in the face of uncertainty and precarity can be seen when the Mutous enter the Shan City compound. A religious organization run by criminals, Shan City is described as a mix between "an alien civilization and a new religion." 32 It is at Shan City that Ayumu comes across Toshio Onodera, a scientist and recurring Japan Sinks character, who is now mute and paraplegic. It is revealed that much of Shan City funds itself through the illicit cultivation of marijuana. Its matriarch, however, doubles as a priestess, who acts as a conduit for her mute son. Here, refugees and members of Shan City can perform séances and communicate with their dead. Still, despite the organization's shadiness, the compound does not discriminate, and most of the people the Mutous interact with seem pleasant and well-meaning. It is also in the Shan City compound that Mari and Ayumu reconcile their relationship, which has become frayed with the death of Koichiro. After a series of earthquakes levels the compound and kills most of its members, the Mutous are forced to leave. 
There are two purposes for the Mutous to end up here. On one, it recalls Komatsu's 1973 novel. Yusuke Tadokoro, Onodera's boss and mentor, drew most of his funding from a new religious movement:

"Well, where does he get the money?" asked Onodera.

"The Church of the Seven Seas," answered Yukinaga cryptically. "It's a new religion. Its headquarters is in Greece." 33

As a new religious organization, Shan City acts as a roundabout diegetic reason as to why Onodera is at the compound. On another level, just like the urban-rural and the visibleinvisible divides, Shan City problematises questions of recovery. In Shan City, the atemporal depiction of rural decay is mapped directly onto the body of its members. At the compound, Go meets a former sumo wrestler (rikishi), whose association with Shan City predates the events of Japan Sinks 2020. In this sense, Shan City is not only an evacuation site, but also doubles as a meeting site for people evacuating more than the disaster. This evacuation imagery is even more important considering that Japan Sinks $202 O$ seeks to grapple with the depiction of private actors, especially private religious actors.

Just as how international broadcasting unveils questions of urban versus rural imaginations, the role of new religious organizations problematize concerns with regards to both physical and spiritual recovery. According to scholar Inoue Nobutaka, new religions have a somewhat uneasy relationship with the overall Japanese population. Even in the age of new media and the internet, mainstream Japanese opinions of new religions have been mainly critical. 34 However, despite the concerns, religious movements - and new religious movements particularly - have played a central part, for better or for 
worse, in recuperative operations after disasters in Japan. Scholar Levi McLaughlin notes that due to paralyzed governmental responses and media depiction, private religious responses during the 1995 Hanshin-Awaji earthquake and the Tokyo Subway sarin gas attack drastically maligned new religious involvement. 35

However, the private religious organizations saw a dramatic shift after 3.11. McLaughlin noted that religious organizations - especially new religions - learned critical public relations lessons from 1995 to lessen the animosity gap between them and the public. ${ }^{36}$ Furthermore, during the initial stages of the disaster, religious organization Soka Gakkai, like many other new religious centers, played crucial roles in taking in refugees while simultaneously suspending proselytization. 37 Within minutes, places like the Soka Gakkai Cultural Center in Sendai became a refugee hub and mobilized an army of rapid response volunteers. ${ }^{8}$ Thus, on the one hand, Shan City serves as a reminder of new religious organizations' role, specifically how they played a critical role in disaster relief. Yet on the other, Shan City also touches upon the tasks of comfort care, of which many religious organizations have more than willing to provide:

The Japanese public has begun looking beyond the traumas of 3.11, and news reports about the many thousands of Tohoku residents who still live with the pains and deprivations of the disasters are growing increasingly less frequent. Religious organizations are some of the few groups that maintained active aid efforts long after international aid agencies and government emergency crews left the area, and they are now working to raise awareness about their activities and to solicit volunteers in the face of dwindling national concern. 39

Moreover, these ongoing efforts are working. In the wake of 3.11, positive media coverage of new religious movements saw a qualitative uptick despite the lack of a quantitative one. ${ }^{\circ}$ Part of this uptick is also due to the ongoing care - both spiritual and physical - that 
many religious organizations offer. Similar to Aoi and Watanabe's definitions of invisible collapse as unseen or unregistered destruction, so too are there neglected or unrecorded recovery efforts. The role of the religious movement, in this case, can be seen as what McLaughlin notes as kokoro no kea, or therapy of the soul. ${ }^{41}$ Therefore, it is no surprise that Ayumu's character undergoes its most dramatic shift in this arc. Not only does she mend her relationship with her mother, but in wondering why Kite remains, she reveals the class dimensions underlying disaster recovery:

Ayumu: How come you didn't leave Japan right away? All the other rich people have left. $4^{2}$

Though not exclusive to new religious movements, much of this therapy iswithin these new religious movements' interest to maintain. These religious organizations, therefore, fall into the previous mediascape patterns - like many of the unspoken or underrepresented elements of the 3.11 mediascape, new religious movements played an indelible role in recovery (and continue to). However, for historical reasons, their coverage has been relatively scant compared to the scale of their involvement. At the same time, Ayumu's question reminds the viewer of these survivors' condition - like members of the hinan shakai, many refugees are those who have lost everything or cannot afford to leave. These religious organizations, in this sense, can be all they have left.

The inclusion of Shan City serves as a performance between the mainstream media and new religions. The show neither outwardly criticizes nor endorses the actions of new religious organizations. Shan City is shown as ominous, though never necessarily dangerous. Even after one of the quakes ripples throughout the compound and places everyone in danger, the central statue at Shan City is flanked by the open gate, reminiscent 
of a figure locked behind closed doors. One of the scientists who attempts to escape with some of Shan City's wealth stops at the gate, unable to move further. There is, in effect, a separation between an imagined community in Shan City, an "Us" that, while the Mutous are not a part of, can nevertheless be witness to their struggles. In this sense, the fact that the Mutous - as a urbanised, Tokyo analogue - can watch the downfall of Shan City reaffirms that recovery efforts, even if doomed, are incredibly vital for its actants. The vastly different experiences of the Mutou children demonstrate the general vitality of these new religions, at least in the context of post-3.11 recovery. It is therefore unsurprising that when the compound begins to collapse, its members choose to stay behind. The scene's emotional gravitas is played straight: the rubble falls in slow motion, the matriarch's narration superimposed as everyone plummets to their deaths:

In this world, no one is useless. Let's build it together!43

On a spiritual and social level, Shan City - as a stand-in for religious organizations - is all they have left.

In this sense, the counter-narrative presented in the Shan City arc is not just to stress the central role of new religious organizations, but also shed light on actors outside of the civilian-government distinction.

\section{Disaster as Recuperation; Body and Mobility}

Japan Sinks 2020 similarly touches upon bodies as sites of political conflict. These fold back onto questions of what it means to be Japanese. In doing so, Japan Sinks 2020 critiques the sense of 'nation' which emerged after 3.11, problematizing what being "Japanese" truly means. For instance, the show takes advantage of the Mutous' character 
design as a source of commentary. Later in the series, the Mutous attempt to board a raft, which is helmed by a far-right ethnonationalist. However, the ferryman does not realise that Mari and Go - both with character designs noticeably darker than most of the characters - are not fully Japanese. It is only at Go's English phraseology that the ferryman becomes suspicious. In this sense, the character design of the Mutous are played to mark the arbitrary nature of ethnonationalist rhetoric, that what constitutes as a pure Japanese citizen is incredibly unclear. This depiction effectively defangs nationalist sentiments, that even the more stringent of Japanese nationalists are unable to differentiate between who is and is not Japanese.

However, the show's body and state relation is at its most striking during discussions of the Olympics, both as a test of the Japanese body and as a test of the Japanese state. The show ends the same way it begins: the Olympics. On the one hand, ending the Olympics is a spectral pall cast over Japan's disasters. Because the Tokyo Olympics were postponed due to the COVID-19 pandemic, to show the lost Japanese returning to a resurging (literally) Japan is emblematic of what Mark Fisher calls a lost future, an object that engages with something bearing a "tantalising ache of a future just out of reach." 44 On the other, more striking hand, ending Japan Sinks 2020 on the Olympics recalls the international image that Komatsu was grappling with by examining the technological politics of the anime genre-medium. It is no coincidence that the first internationally broadcast Japan Sinks media not only comes out in the shadow of a postponed Olympics, but also aggressively depicts Japan and its citizens as anything but calm and collected, a far cry from the ongoing 3.11 media narrative it draws upon. In doing so, Science SARU problematizes the idea that Japan has 'recovered' from 3.11. 
The intertwining of Japan Sinks with disaster and disaster representation in a global context has been an unshakeable element of the media mix. Marc Steinberg notes that two events drove home televisions' sales: the broadcasting of (then) Crown Prince Akihito and the 1964 Tokyo Olympics. 45 Furthermore, we can recall that Komatsu himself began writing the original Japan Sinks novel as a response to the Tokyo Olympics. ${ }^{46}$ The role of television and recovery is thus interlocked; the postwar Japan images were primarily through the Olympics, broadcast on television. On a literal basis, what is reflected in those Olympics was a Japan that has recovered and rebuilt itself from the war. On a more general basis, the Olympics in Japanese media combine both questions of nation and body together; the Olympics are a test of physical and mental prowess, an encapsulation of people of a nation or state, and thus their success is an affirmation of that state's own success.

As a Netflix show, Science SARU's Japan Sinks 2020 initially mimics that Olympic scene, though quickly problematizes that imagery. Ayumu, a competitor, takes off her jacket, revealing a prosthesis. Her wound is permanent. Here, the raucous and joyous imagery of a resurging Japan symbolizes a turn of phrase by pastor Tomoshi Okuda, who notes that bonds (kizuna) contain wounds. 47 To recall Mihic, Japan experienced a resurgent sentimentality through the rhetoric of kizuna. However, despite these recovery efforts, Okuda warns us that such bonds emerge from genuine human suffering. 48 Therefore, the permanence in Ayumu's prosthesis is a visible marker of her status as a survivor of disaster, reminding viewers that such disasters leave permanent wounds. The show folds back previous discussions about national-international and visible-invisible images on itself as a critique. Damage and destruction become sites where national and international (who is watching versus who is recovering) and visible versus invisible (what 
is fixed versus what is lost) intertwine. Ayumu is not only a Japanese subject being watched by an international audience, but a stand-in for Japan; she moves on from the sexual assault, violence, gruesomeness, the loss of friends and family, to emerge triumphant at the new Olympics. However, despite her triumph, the loss of her leg is an irreparable marker of her status as one who ultimately loses: she loses friends, family members, and home. The disaster, even after Ayumu has "recovered," has shaped her. Thus Japan Sinks 2020 serves as a reminder that such disasters are not temporary disruptions of time and space but permanently mark the bodies - literal and political caught within them. This lens marginalizes the glorification of recovery, stressing that rebuilding is not something subjects acquire but mould.

Ayumu's wound as the hijacking of nationalist sentimentality is not unique to Japan Sinks 2020. Beginning before the postwar period, the discussion of the political state of affairs is often conducted on the state of the Japanese body. To Yoshikuni Igarashi, "the discursively constructed body becomes the central site for the reconfiguration of Japan's nationalist discourse," 49 and while 3.11 is not a war, there was a surge of nationalist discourse during reconstruction.50 In this light, the frequent depiction of bodies - running, wounded, crushed, destroyed, and recovering - serves as a marker for the ongoing political state. Ayumu's prosthesis is not the only time she runs, nor is she the only runner: her upperclassman Haruo Koga was a former runner, with the show depicting his sprint to his death. Likewise, when the initial quake destroys her training facility and kills her friends, Ayumu runs home.

Running as a motif is not unique to Japan Sinks 2020. Science SARU's previous Netflix broadcast, Devilman Crybaby, also heavily features characters and their bodies in states of motion. However, what makes the running in Japan Sinks 2020 especially 
important is that one of the few characters endemic to the Japan Sinks franchise Onodera - is completely immobile. Onodera's immobility can be seen as a symbol of the Japanese government; a technocrat incapable of acting on his own, with access to confidential information on the future of the country, and yet is always reliant on younger, newer bodies to implement his plans. While Onodera knows of the location of Tadokoro's server, it was ultimately Kite who found the data, and it was ultimately Koga who saved it after it was nearly washed out to shore, at the cost of his own life. Concurrently, all runners ultimately perish, save for Ayumu.

In showing Ayumu's prosthesis and the permanence of her wound, Japan Sinks: 2020 reminds the audience of the disaster's impact. Regardless of the mirth, the event cannot ever be over since it has already shaped the victims within it. In this light, Japan Sinks: 2020 brings forward something to the international mediascape: disaster itself, a consistent and insistent reminder of the cost such events impute upon those caught within it. At the same time, if the body can be seen as an extension of the national political order, then Ayumu's wound reflects the same imagery of old, spectral Japan. Ayumu's loss of her foot is not just a consequence of the disaster, but one in the same; the show intercuts between a jovial Olympic ceremony existing between two striking images of inescapable tragedy. One on hand, a promising young girl who has lost not only a limb, but also much of her family. On the other, an entire nation and political body sunk beneath the waves. The supposed "recovery" can be seen as a sort of symbolic act, ${ }^{51}$ where insurmountable contradictions are resolved aesthetically, a form of suturing which prevails the preexisting ideological order. Given that Japan Sinks 2020 was originally meant to broadcast alongside the Tokyo 2020 Olympics, the ending imagery serves as a sort of counternarrative to any presuppositions that Japan has sufficiently recovered from the 
events of 3.11. The resurgent Olympics of Japan Sinks 2020 is hosted, in effect, on the remains of a sunken Japan with participants who were the victims of such sinking. Much like the real-life Tokyo Olympics, there is arguably no clear resolution yet - some, many, have moved on, yet the show demonstrates that such resolutions are merely masks for ongoing concerns in Japan today.

In this sense, each element of Japan Sinks; 2020 reshapes an aspect of disaster rhetoric in its own way: the regional-national, urban-rural divisions remind viewers that disasters need not be explosive cataclysms to be destructive. The sexual violence and radiation indicate invisible disasters, ongoing and long-lasting devastations that immediate patchwork solutions cannot easily solve. The new religious compounds problematize the idea that disaster events can have limits, contesting the idea that once the homes are rebuilt, that everything is over. In reality, long-lasting recovery is itself a political process. Finally, Ayumu serves as a pointed question as to whether subjects can truly overcome disasters.

\section{Conclusion}

Every Japan Sinks text critically engages with what Japan means when a Japanese ontology is examined. When the country goes under, several fundamental questions are asked: who is to be saved, how do we save them, who are our allies, and where do we go from here? These questions and answers are partly drawn from the real disasters that have shaped Japan. For the 1973 novel and 1974 film, it was the postwar recovery and Oil shock. For the 2006 novels and film, it was a post 9/11 security precarity. For Science SARU's Japan Sinks 2020, it was 3.11. These concerns about defining and witnessing are especially important given that just as the eyes of the world were on Japan once more, there was another disaster - COVID-19 and the postponement of the Tokyo Olympics. 


\section{DIAMS}

Japan Sinks 2020 acts as a stark reminder of the challenges of recovery and survival and how others perceive that recovery and survival. And what is it showing? It turns out, there is no real "recovered" Japan, but rather a post-disaster Japan, waiting for another event to discombobulate the country once again. In this sense, the counter-narrative broadcasted by Japan Sinks 2020 portrays neither a calm, cool, nor collected Japan, but rather one already straddling uncertainty, rural decay, and ultimately invisible problems. 


\section{Notes:}

${ }^{1}$ Brett Homenick, “Sakyo Komatsu on Science Fiction! Japan's Arthur C. Clarke Discusses His Filmmaking Foray!" Vantage Point Interviews, accessed February 6, 2021, https://vantagepointinterviews.com/2017/04/27/sakyo-komatsu-on-science-fiction-japansarthur-c-clarke-discusses-his-filmmaking-foray/.

${ }^{2}$ Rebecca Suter, "Disaster and National Identity: The Textual Transformations of Japan Sinks," in When the Tsunami Came to Shore, ed. Roy Starrs (Brill 2015), 215.

3 Richard Llloyd Perry, Ghosts of the Tsunami: Death and Life in Japan's Disaster Zone (New York: Ferrar, Straus, and Giroux, 2017), 12

4 Perry, "Ghosts of the Tsunami," 12.

5 "Outline of Decommissioning and Contaminated Water Management," Secretariat of the Team for Countermeasures for Decommissioning and Contaminated Water Treatment, accessed February 9, 2021, https://www.meti.go.jp/english/earthquake/nuclear/decommissioning/pdf/mp202012.pdf. ${ }^{6}$ Suter, "Disaster and National Identity," 214.

7 Mihic, Tamaki. Re-imagining Japan after Fukushima, Australian National University Press (Sydney, 2020): 12.

${ }^{8}$ Mihic 14.

9 Yuko Nishimura, “A Tohoku Utopia? Alternative Paths After March 11, 2011,” Global Ethnographic, last accessed February 9, 2021, https://globalethnographic.com/index.php/atohoku-utopia-alternative-paths-after-march-11-2011-2/.

10 Nishimura, "A Tohoku Utopia?"

${ }^{11}$ Appadurai, Arjun, "Disjuncture and Difference in the Global Cultural Economy," Public Culture, no. 2 (1990): 9.

12 "Nihon chinbotsu 2020" kazoku no shiten kara kaku riaru na genjitsu," Nikkei Entame, last accessed February 6, 2021, https://style.nikkei.com/article/DGXMZO62515040R10C20A8000000/.

${ }_{13}$ "Prefectures with the highest level of income according to Japanese residents as of November 2019," Statista, last accessed February 15, 2021, https://www.statista.com/statistics/1087537/japan-prefectures-high-income-level/.

14 Lamarre, Thomas. The Anime Machine: A Media Theory of Animation, University of Minnesota Press, Minneapolis (2009): 18.

15 Yuko Nishimura, "A Tohoku Utopia? Alternative Paths After March 11, 2011," Global Ethnographic, last accessed February 9, 2021, https://globalethnographic.com/index.php/atohoku-utopia-alternative-paths-after-march-11-2011-2/.

${ }^{16}$ Nishimura, "A Tohoku Utopia?"

17 Kimiko de Freytas-Tamura, "Radioactive Boars in Fukushima Thwart Residents' Plans to Return Home," The New York Times, last modified March 9, 2017, https://www.nytimes.com/2017/03/o9/world/asia/radioactive-boars-in-fukushima-thwartresidents-plans-to-return-home.html.

18 Julian Ryall, “Ageing Japanese towns overrun by wild boars," The Telegraph, last modified March 10, 2018, https://www.telegraph.co.uk/news/2018/03/10/ageing-japanese-townsoverrun-wild-boars/.

${ }_{19}$ Usamaru Furuya, Kanojo wo Mamoru 51 no houhou 3 (Tokyo: Shinchosha, 2007) pg 159. 20 Ibid 158.

${ }^{21}$ Nishimura, "A Tohoku Utopia?”

22 Tamaki Mihic, Re-imagining Japan after Fukushima (Canberra: ANU Press, 2020), 139.

23 Japan Sinks: 2020 episode 3 
24 "Gender-based Violence Following the 2011 Great East Japan Disasters: Making the Invisible Visible through Research,” Michigan Social Work, last modified August 4, 2017, https://ssw.umich.edu/stories/53271-gender-based-violence-following-the-2011-great-eastjapan-disasters-making-the-invisible-visible-through-research.

${ }_{25}$ Rob Gilhooly, "Subtle aid for women facing abuse in disaster-hit areas," The Japan Times, last modified October 1, 2011, https://www.japantimes.co.jp/community/2011/10/o1/general/subtle-aid-for-women-faRcingabuse-in-disaster-hit-areas/.

${ }_{26}$ Takahiko Yasuda, Yusuke Takayama, and Katsuhiro Soma, "Activities of Japanese police in the Great East Japan Earthquake,” Journal of International Criminal Justice Research 1 (2014): 6 .

27 "Gender-based Violence Following the 2011 Great East Japan Disasters."

${ }_{28}$ Akihito Aoi, "Mienai houkai to ha - watashitachi no chikudukuri no kihonteki na kaehou,"

Medium, last accessed February 20, 2021, https://medium.com/見えない災害-の風景/O2-見え ない災害とは-2264e48233e3.

29 Saito, Mari. Fukushima farmer takes on Tepco over wife's suicide, https://www.japantimes.co.jp/news/2014/07/10/national/fukushima-farmer-takes-tepcowifes-suicide/

$3^{30}$ Allison, Anne. Precarious Japan, Durham (Duke University Press, 2013): 66.

${ }^{31}$ Allison, 66.

$3^{2}$ Toshio Yoshitaka, Nihon Chinbotsu 2020 (Bungeishunju, 2020), 51. The exact kanji used was 新興宗教.

33 Sakyo Komatsu, Japan Sinks, translated by Michael Gallagher (New York: Dover Doomsday Classics, 2016), 44.

34 Inoue Nobutaka, "Media and New Religious Movements in Japan,” Journal of Religion in Japan 1, no. 2 (January 2012): 139.

35 Levi McLaughlin, "Hard Lessons Learned: Tracking Changes in Media Presentations of Religion and Religious Aid Mobilization after the 1995 and 2011 Disasters in Japan," Asian Ethnology 75, No. 1 (2016): 107.

${ }^{36}$ McLaughlin, "Hard Lessons Learned," 108.

37 Levi McLaughlin, "What Have Religious Groups Done After 3.11? Part 1: A Brief Survey of Religious Mobilization after the Great East Japan Earthquake Disasters," Religion Compass 7, no.8 (2013): 302-303.

$3^{8}$ Ibid.

39 Levi McLaughlin, "What Have Religious Groups Done After 3.11? Part 2: From Religious Mobilization to 'Spiritual Care'," Religion Compass 7, no.8 (2013): 319.

$4^{\circ}$ McLaughlin, "Hard Lessons Learned," 125.

${ }^{41}$ McLaughlin, "Hard Lessons Learned," 127.

$4^{2}$ Japan Sinks 2O2O, Episode 5

43 Japan Sinks 2020, episode 5

44 Mark Fisher, Ghosts of my life: Writings on depression, hauntology and lost futures

(Winchester: Zero Books, 2014): 98.

45 Steinberg, Anime's Media Mix, 10.

${ }^{46}$ Ide Kazuko, "Japan Sinking? Sequel to 1970 s Novel finds Japan Sunk and the Japanese Scattered," The Asia-Pacific Journal 4, no. 4 (2006).

47 “'Kodoku wa seifude wa kaisho dekinai' NPO riji-cho ga kataru shien no arikata," AERA, last accessed February 18, 2021, https://dot.asahi.com/aera/2018083000061.html?page=1. The exact phrasing is 絆は傷を含む (kizuna ha kizu wo fukumu)。Okuda is playing with the pronunciation of kizuna (きずな) to mean both bonds, which was the kanji of the year in 2011, and a wound.

48 Ibid. 


\section{LIAMS}

49 Yoshikuni Igarashi, Bodies of Memory: Narratives of War in Postwar Japanese Culture, 1946-1970 (Princeton University Press, 2000): 13.

50 Mihic 13.

${ }^{51}$ Frederic Jameson, The Political Unconscious: Narrative as a Socially Symbolic Act (New York: Cornell University Press): 77. 


\section{Bibliography:}

Aoi, Akihito. "Mienai houkai to ha - watashitachi no chikudukuri no kihonteki na kaehou." Medium. Last accessed February 20, 2021. https://medium.com/見えない災害-の 風景/02-見えない災害とは-2264e48233e3.

Appadurai, Arjun. "Disjuncture and Difference in the Global Cultural Economy." Public Culture 2, no.2 (1990): 1-24.

Fisher, Mark. Ghosts of my life: Writings on depression, hauntology and lost futures. Winchester: Zero Books, 2014.

Freytas-Tamura, Kimiko, de. "Radioactive Boars in Fukushima Thwart Residents' Plans to Return Home." The New York Times. Last modified March 9, 2017. https://www.nytimes.com/2017/03/o9/world/asia/radioactive-boars-infukushima-thwart-residents-plans-to-return-home.html.

Furuya, Usamaru. "Kanojo wo mamoru 51 no houhou 3." Tokyo: Shinchosha, 2007.

"Gender-based Violence Following the 2011 Great East Japan Disasters: Making the Invisible Visible through Research," Michigan Social Work, last modified August 4, 2017, https://ssw.umich.edu/stories/53271-gender-based-violence-followingthe-2011-great-east-japan-disasters-making-the-invisible-visible-throughresearch.

Gilhooly, Rob. "Subtle aid for women facing abuse in disaster-hit areas." The Japan Times. Last modified October $1, \quad 2011$. https://www.japantimes.co.jp/community/2011/10/o1/general/subtle-aid-forwomen-faRcing-abuse-in-disaster-hit-areas/.

Homenick, Brett. “Sakyo Komatsu on Science Fiction! Japan's Arthur C. Clarke Discusses His Filmmaking Foray!” Vantage Point Interviews. Last accessed February 6, 2021. https://vantagepointinterviews.com/2017/04/27/sakyo-komatsu-on-sciencefiction-japans-arthur-c-clarke-discusses-his-filmmaking-foray/

Igarashi, Yoshikuni. Bodies of Memory: Narratives of War in Postwar Japanese Culture, 1945-1970. Princeton: Princeton University Press, 2000.

Jameson, Frederic. The Political Unconscious: Narrative as a Social Symbolic Act. New York: Cornell University Press, 1981.

Kazuko, Ide. "Japan Sinking? Sequel to 1970s Novel finds Japan Sunk and the Japanese Scattered." The Asia-Pacific Journal 4, no. 4 (2006). https://apjjf.org/-IdeKazuko/2228/article.html.

“Kodoku wa seifude wa kaisho dekinai' NPO riji-cho ga kataru shien no arikata." AERA. $\begin{array}{llll}\text { Last } \quad \text { accessed } & \text { February } & \text { 18, }\end{array}$ https://dot.asahi.com/aera/2018083000061.html?page $=1$.

Komatsu Sakyo. Japan Sinks. Translated by Michael Gallagher. New York: Dover Doomsday Classics, 2016.

Langer, Jessica. “Three versions of Komatsu Sayko's Nihon Chinbotsu (Japan Sinks).” Science Fiction Film and Television 2, no. 1 (2009): 45-57. https://muse.jhu.edu/article/269119/pdf

McLaughlin, Levi. "Hard Lessons Learned: Tracking Changes in Media Presentations of Religion and Religious Aid Mobilization after the 1995 and 2011 Disasters in Japan.” Asian Ethnology 75, No. 1 (2016): 105-137. 
McLaughlin, Levi. "What Have Religious Groups Done After 3.11? Part 1: A Brief Survey of Religious Mobilization after the Great East Japan Earthquake Disasters." Religion Compass 7, no.8 (2013): 294-308.

McLaughlin, Levi. "What Have Religious Groups Done After 3.11? Part 2: From Religious Mobilization to 'Spiritual Care'.” Religion Compass 7, no.8 (2013): 309-325.

Mihic, Tamaki. Re-imagining Japan after Fukushima. Canberra: ANU Press, 2020.

Napier, Susan. "Panic Sites: The Japanese Imagination of Disaster from Godzilla to Akira." Journal of Japanese Studies 19, no. 2 (1993): 327-351. https://doi.org/10.2307/132643

"Nihon chinbotsu 2020" kazoku no shiten kara kaku riaru na genjitsu." Nikkei Entame. Last accessed February 6, 2021. https://style.nikkei.com/article/DGXMZO62515040R10C20A8000000/.

Nishimura, Yuko. "A Tohoku Utopia? Alternative Paths After March 11, 2011." Global Ethnographic. Last accessed February 9, 2021. https://globalethnographic.com/index.php/a-tohoku-utopia-alternative-pathsafter-march-11-2011-2/.

Nobutaka, Inoue. "Media and New Religious Movements in Japan." Journal of Religion in Japan 1, no. 2 (January 2012): 121-141. https://doi.org/10.1163/221183412X645308

"Outline of Decommissioning and Contaminated Water Management." Secretariat of the Team for Countermeasures for Decommissioning and Contaminated Water $\begin{array}{lllll}\text { Treatment. } & \text { Last } & \text { accessed } & \text { February }\end{array}$ https://www.meti.go.jp/english/earthquake/nuclear/decommissioning/pdf/mp 202012.pdf

Perry, Richard Lloyd. Ghosts of the Tsunami: Death and Life in Japan's Disaster Zone. New York: Ferrar, Straus, and Giroux, 2017.

"Prefectures with the highest level of income according to Japanese residents as of November 2019." Statista. Last accessed February 15, 2021. https://www.statista.com/statistics/1087537/japan-prefectures-high-incomelevel/.

Ryall, Julian. "Ageing Japanese towns overrun by wild boars." The Telegraph. Last modified March 2018. https://www.telegraph.co.uk/news/2018/03/10/ageing-japanese-townsoverrun-wild-boars/.

Shilling, Mark. “The Sinking of Japan.” The Asia-Pacific Journal 4, no. 8 (August 2006). https://apjjf.org/-Mark-Schilling/2188/article.html

Steinberg, Marc. Anime’s Media Mix. Minneapolis: University of Minnesota Press, 2012.

Suter, Rebecca. "Disaster and National Identity: The Textual Transformations of Japan Sinks." In When the Tsunami Came to Shore, edited by Roy Starrs, 214-229. Brill, 2015 .

Takahiko Yasuda, Yusuke Takayama, and Katsuhiro Soma. "Activities of Japanese police in the Great East Japan Earthquake." Journal of International Criminal Justice Research 1 (2014), 1-19. https://www.aabri.com/manuscripts/131480.pdf.

Tsunehiro Uno. Zero nendai no sozoryoku. Tokyo: Hayakawa Shobou, 2008.

Yoshitaka, Toshio. Nihon Chinbotsu 2020. Bungeishunju, 2020. 